Copyright (C) 2021 The Author/s

This work is licensed under a CC-BY 3.0 License

Peer review method: Double-Blind

Accepted: August 16, 2021

Published: September 21, 2021

Original scientific article

DOI: https://doi.org/10.47305/JLIA2137050d

\title{
SCOPE OF MEDIA ADVOCACY DURING COVID-19: A SELECTED CASE STUDY IN KOLKATA
}

\author{
Rajesh Das \\ The University of Burdwan, West Bengal, India \\ ORCID iD: https://orcid.org/0000-0002-2493-2027 \\ rd.icssr@gmail.com
}

\section{Ipsita Banerjee*}

ICSSR-IMPRESS (MHRD), the University of Burdwan, West Bengal, India

ORCID iD: https://orcid.org/0000-0002-0435-7387

ipsitabanerjee95@gmail.com

\begin{abstract}
The spread of the Covid-19 has presented an unparalleled challenge for media management as well as for the media content. The pattern of daily life changed due to the excessive use of media. India, as a nation has been in the third position worldwide, many deaths during a pandemic are concerned. Kolkata being one of the metro cities of the country has not been exempted. The regional media content perceived a knowledge gap with the highest circulated national daily of the country. The changed media content, and audience perception towards the change, and the need for media advocacy during any health crisis in general and Covid-19 in particular, is studied in this paper using a mixed approach of both quantitative and qualitative. The discourse analysis of the newspapers in a constructed week format, representing a six months study during the pandemic, and the primary data from the audience suggested the behavior change and attitude formation through media, in this unique study.
\end{abstract}

Keywords: Covid-19; Kolkata; Newspapers; Media; Consumption; Media Advocacy

\section{INTRODUCTION}

The Covid-19 crisis has impacted all sections of society in an unprecedented manner. Apart from inducing panic and uncertainty amidst the general population, the pandemic has also significantly disrupted the way of business processes, sociological framework, academic and research curriculum, and mode of income generation activities. Due to the reduced mobility, social distancing, panic of quarantine, and lockdown, the extent of media consumption has played a crucial role to form awareness about this pandemic. The media content plays a decisive role in terms of combating misinformation and providing credible information on the Covid-19 pandemic. 
A new paradigm of 'structure-conduct-performance' (SCP), about media content, has emerged in the present society. The emphasis "on the communicative powers of the media direct us to more than just an acknowledgment that the media are a potential influence of modern life" (Craig 2007). So to say, news and views of the Covid-19 pandemic have been able to clarify various issues of behavioral changes and communication on socio-cultural and socio-psychological perspectives. Mumbai, Delhi, Kolkata are amongst the Indian major cities where the Covid-19 pandemic has produced its major impact and where lockdown measures have been the harshest. The present paper tries to understand how the corona crisis has been symbolized in Indian media in general and Kolkata-based selected dailies in specific. Till today, newspapers give us a space that creates a general opinion of the public through different forms of "column" (Jeffery 2000). In this crisis period, the newspaper also retains great power in the society through its comments, suggestions, and criticism regarding the Covid-19 issue. At the same time, media content could create some misinformation and confusion regarding the Corona virus in the public sphere instead of generating a credible and useful information network for public awareness. In this contradictory experience, this research aims to identify the degree of media advocacy during the Covid-19 pandemic in Kolkata, based on selected newspaper content.

\section{AIMS AND OBJECTIVES}

This research aims at identifying the media advocacy practiced/published followed by newspapers during the Covid-19 pandemic in Kolkata. The major objectives of this research are:

1. To analyze the contents being published by newspapers in Kolkata, during the Covid-19 pandemic and the degree of acceptance of readers related to these newspaper contents; and

2. To study the scope and issues of media advocacy for effective health communication through a newspaper during the Covid-19 pandemic.

The first objective of this research has been trying to evaluate the extent of acceptance of newspapers and their contents among the readers. The second objective of this research is trying to analyze whether health advocacy has been done by newspapers in the premise of the Covid-19 pandemic. Based on this aim and objectives of the research both primary and secondary data were collected for this research work. 


\section{THE LITERATURE REVIEW}

In the case of print media, there are four keys to interpret the media message. These are 'process, context framework, and production value'. News and/or views regarding public health communication, like the Covid-19 pandemic in India, should justify four rapid sequences of activity under the media advocacy process. These are a) receiving a message; b) selecting relevant information; c) framing appropriate responses, and d) responding to the message (Silverblatt 2001). The news content and readers formulate a 'communication contract' that governs their conduct. A newspaper like the Times of India (TOI), puts news, column, and editorial in perspective, serves as a forum for debate and also presents a point of view on the Covid-19 pandemic for the consideration of its readers. On the other hand, McQualil (1997) opined that to identify the effectiveness of a medium, factors like the duality of audience and audience as a market are required to be considered through audience analysis. Vilbert (2021) further argued that after the outbreak of the Covid-19 pandemic many debates are arising on issues with global health governance.

To create effective advocacy (through interpretation of message), a specific catalyst is needed over the final media product and its presentation. The persuasive function opened up a new strategy of media advocacy with readers. This paper has been studied a bio-cultural approach to pandemics such as Covid-19. Hence, media advocacy tries to introduce anthropogenic dynamics in its content. From the beginning, the Covid-19 pandemic has interacted between socio-cultural, behavioral study, and political factors of society with a pathogen - Coronavirus (Friedler 2020). Therefore to generate a positive attitude with the society and collective combating against such pathogen media advocacy should emphasize bio-cultural understanding to its readers. Eventually, it is observed that a bio-cultural viewpoint of media text on the Covid-19 epidemic will allow for critical reflection on how culture shapes one's behavior at family and community levels.

In public health, the said perspective of media advocacy supports direct attention to the role of policymakers and community-level factors in health promotion. Again this environmental perspective contains a physical and a social element that brings an interdisciplinary notion of public health issues. This advocacy-based strategy works on two levels. First of all, its (newspaper content) effects on individuals and health and finally its effects on health policy. So media advocacy on the Covid-19 pandemic will try to focus the spotlight on the problem upstream (Walsh 2017). Here media advocacy attempts to influence the existing policies taken by international organizations, concerned national governments, or community people. Here the agenda-setting process follows a hierarchy - from media agenda to public agenda, from public agenda to policy agenda (Singhal 2003). In this process, media advocacy supports personal experience or even interpersonal communication among the different stratum of the 
public in society. The multifaceted conceptions regarding the Covid-19 pandemic have shifted the focus from the personal to the social, from the individual to the community, from bio-cultural to political, and from the practice to the policy (Friedler 2021). Conventional strategies of mass media try to identify and fill the knowledge gap where the media advocacy approach opens to speak about the power gap. Based on community advocacy this approach sets a goal about how to promote healthy and acceptable public policies. Thirumaran et al. (2021) opined that the newspaper is effectively used in Singapore and New Zealand for the portrayal of crisis management during the Covid-19 pandemic. Allen and Ayalon (2021) counter opined that in the case of America newspaper articles are causing panic among the people during the crisis of the Covid-19 pandemic. This can be shocking and even deceptive for the audience. The authors Choi and McKeever (2019) further emphasized the fact that the concepts of mobilization of information and media advocacy are interrelated to the situation of an epidemic or a pandemic. According to Chukwu-Okoronkwo (2020), the dissemination of information has a major role to play in the life of people who are marginalized especially during a pandemic. Hence, it was further opined by the authors that dynamic initiative for media promotion and media advocacy is required during a pandemic so that better awareness is promoted among people.

The Literature Gap

From the review of existing literature, it is observed that there is a considerable number of existing researches done on media advocacy and the role of the newspaper during the Covid-19 pandemic yet there is a lack of such research to be done from the perspective of India. Hence, this is a literature gap that is being addressed with the help of this present study so that it can reflect the role of newspapers during this pandemic phase and the extent of media advocacy observed in them.

\section{METHODOLOGY}

This research methodology has been designed considering the concept of research onion structure.

Research Philosophy

This research has been based on the interpretivist research philosophy where the observations are further interpreted using different theoretical foundations and qualitative research along with quantitative research for deriving the research results. Other philosophies like positivism realism and pragmatism were not applicable for the present research (Pham et al. 2018). 
Research Approach

This research follows the deductive research approach where theoretical foundations regarding the research subject area were studied at first and then the process of data collection and interpretation was conducted (Woiceshyn and Daellenbach 2018).

Research Design

Using a descriptive research design has been applicable for this research because this research design helps to explore new segments of an existing research phenomenon. Research on newspapers is common in media research sectors but finding its application during Covid-19 is comparatively new which is why a descriptive research design has been selected.

Data Collection

At first two newspapers, based on the highest rate of circulation in Kolkata, have been selected. Then, the method of the constructed week had been followed to design 3 constructed weeks (Riffe et al. 1993). The months were selected from 15 April 2020 to 15 September 2020 which was the peak phase of Covid-19 in India (please see Annex 1). In the case of primary data collection, respondents 125 from Kolkata were selected using random sampling.

Data Analysis

For qualitative data discourse analysis has been carried out. In the case of quantitative data, the analysis has been done using graphs and statistical elements like chi-square and cross-tabulation using SPSS.

\section{RESULTS}

The results chapter of this research has been divided into two different categories. Here, the first category has tried to explore the results of primary data using quantitative analysis. The second category has helped to evaluate the results from secondary data using qualitative data analysis. 


\section{Primary Data Analysis}

This primary data analysis has been conducted with 125 respondents and the results have been analyzed using percentage analysis and statistical data analysis. For statistical data analysis, SPSS has been used to further analyze the results.

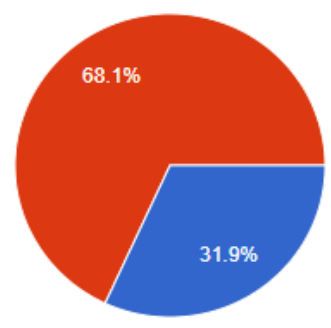

The Times of India

- Anandabazar Patrika

Graph 1: Newspaper Readers for Anandabazar Patrika and the Times of India (Source: Authors' depiction)

Graph 1 observes that the maximum number of respondents that is $68.1 \%$ have read Anandabazar Patrika a Bengali daily circulated in Kolkata and other parts of West Bengal. On the other hand, only $31.9 \%$ of the rest of the respondents have read the Times of India, English daily circulated in Kolkata and other parts of West Bengal.

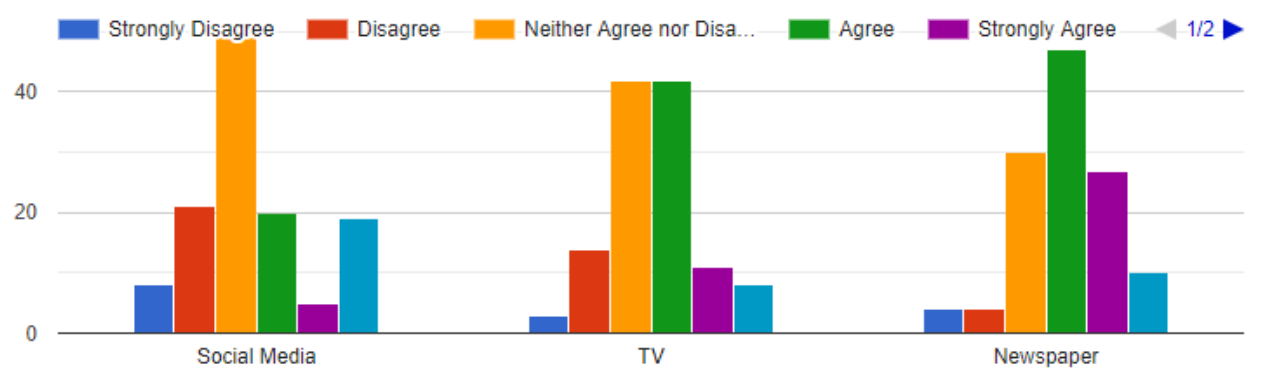

Graph 2: Media Credibility and Authenticity (Source: Authors' depiction)

From Graph 2 it can be observed that more respondents have agreed in favor of the media credibility and authenticity of news published in newspapers. 


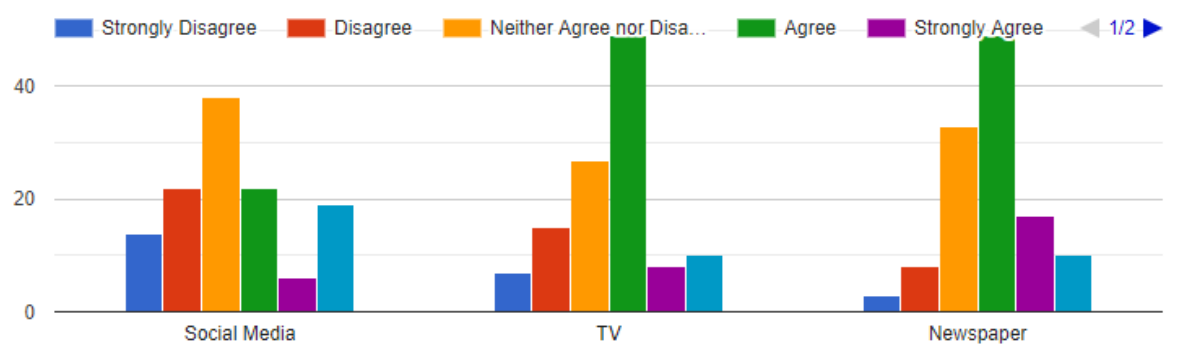

Graph 3: Promotion of the Scientific Approach (Source: Authors' depiction)

When it comes to the promotion of the scientific approach then newspapers and television have got an almost equal number of responses from the respondents who have agreed to the statement.

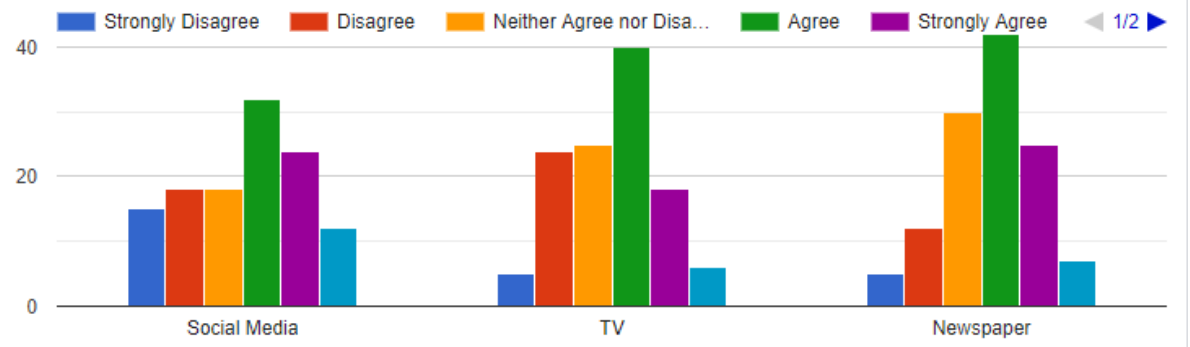

Graph 4: Reducing Social Taboo (Source: Authors' depiction)

In the case of the newspapers, the maximum number of respondents agreed to the statement that it helps in reducing social taboos. Furthermore, it can be observed that the number of respondents with green for the newspaper is more than that of the number of respondents who agreed to the statement applicable for television and social media. Hence, in this case, as well it can be explained that the newspaper is the most effective medium for reducing social taboos as perceived by the respondents (Graph 4).

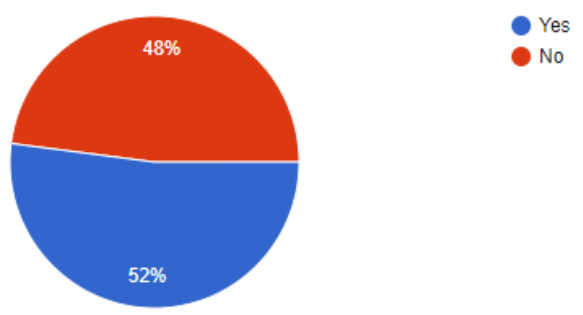

Graph 5: The Element of Fear Promoted By Negative Representation of News (Source: Authors' depiction) 
As per Graph 5, 52\% of the respondents being the majority expressed that there is a negative representation of search in the news that increases the fear element associated with the Covid-19 pandemic.
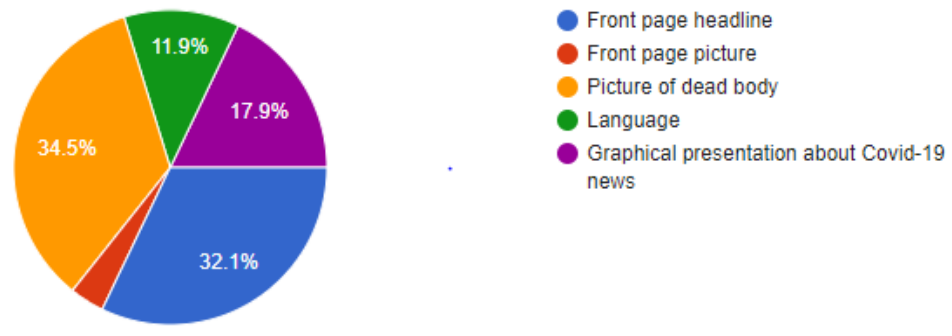

Graph 6: The Mostly Observed Fear Element Used in the Newspapers (Source: Authors' depiction)

It can be further analyzed that $34.5 \%$ of the respondents express that pictures of dead bodies are the most disturbing elements in newspapers that increase their fear of the Covid-19 pandemic. Furthermore, 32.1\% of the respondents expressed that the front-page headline is the element that increases their fear of the disease after reading the newspaper.

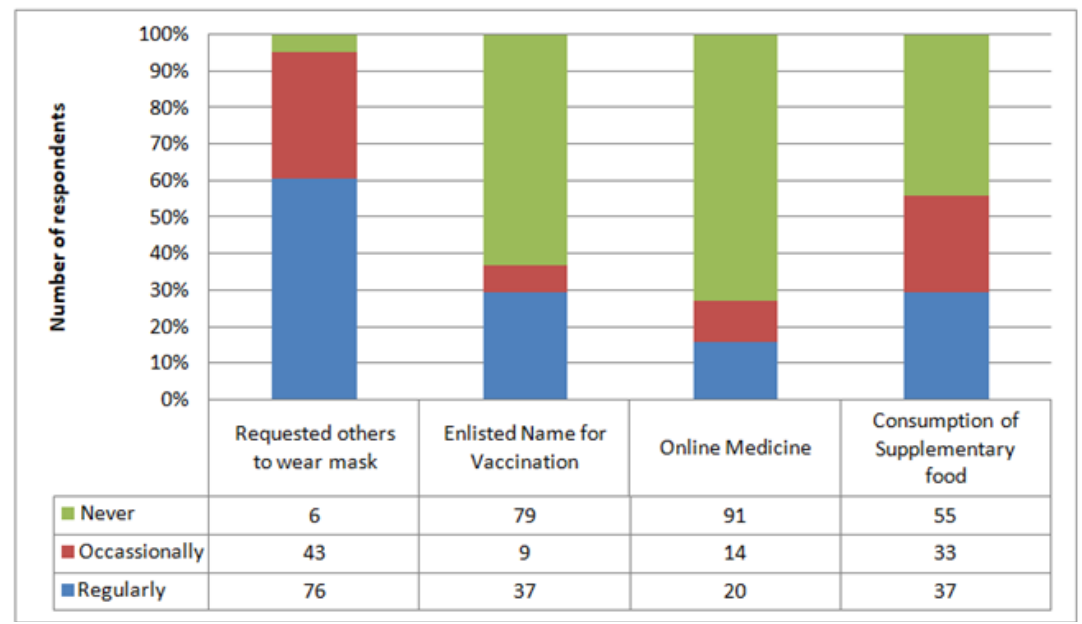

Graph 7: The Preventive Measures Used (Source: Authors' depiction)

Graph 7 emphasizes the measures that are taken up by the respondents as precautions against the pandemic. 


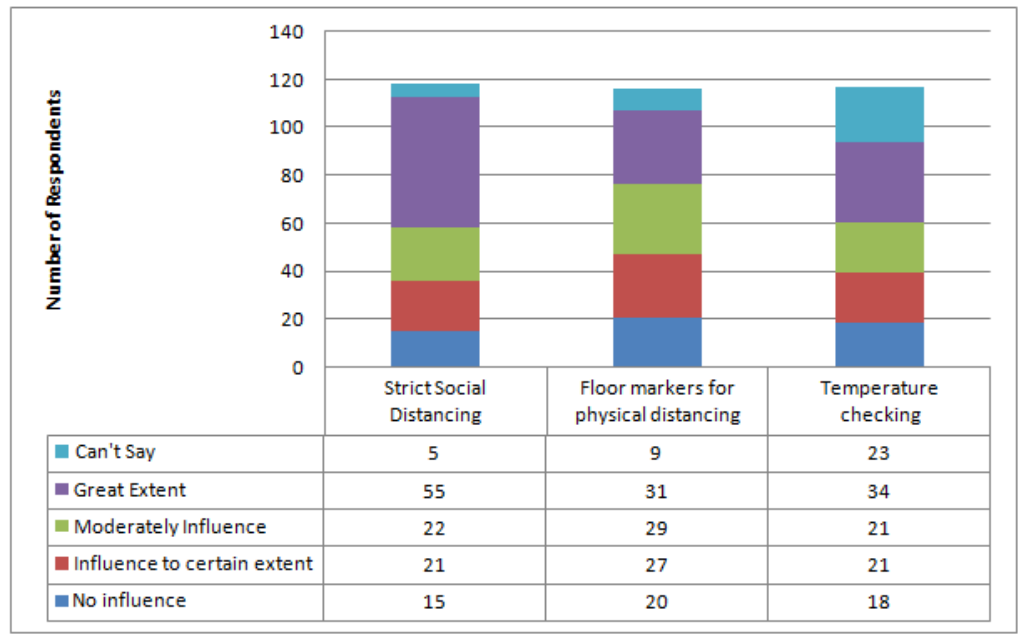

Graph 8: Factors That Increases the Confidence of People to Fight against the Pandemic (Source: Authors' depiction)

From Graph 8, it can be concluded that strict social distancing has influenced the confidence level of the respondents to a greater extent than that of the other factors observed in this graph.

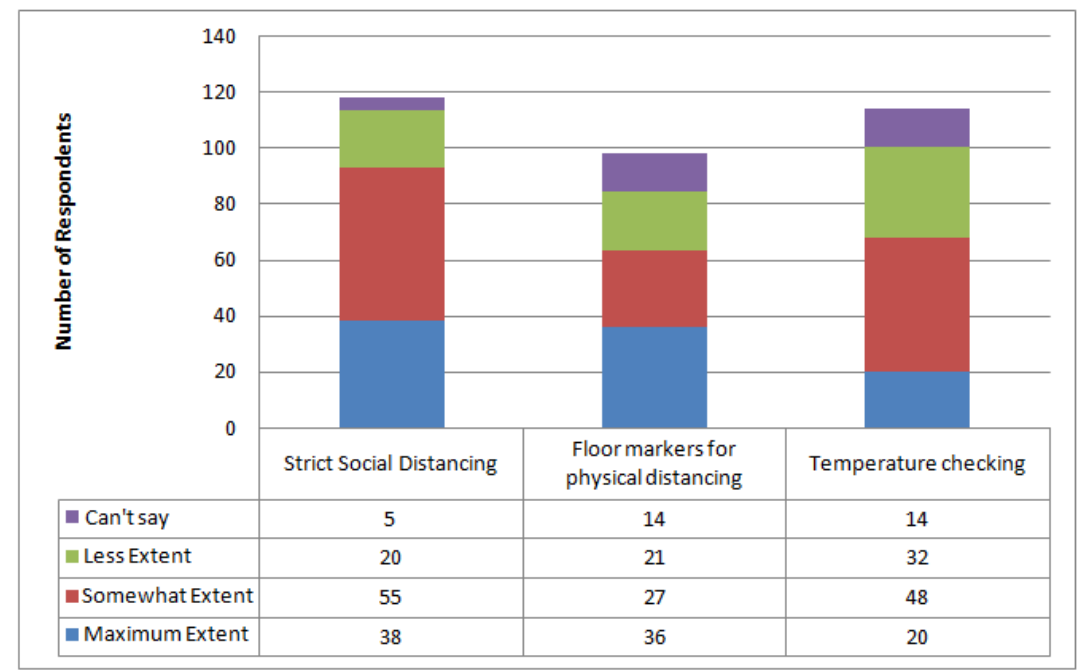

Graph 9: Reflection of Factors in the Newspapers (Source: Authors' depiction)

Graph 9 reflects the above factors and their representation in newspapers. In the case of social distancing, the newspaper reports reflect them to some extent as expressed by the majority of respondents. On the other hand floor markers for physical distancing are being reflected the maximum extent as open by the majority of respondents. 


\section{The Demographic Details v/s News Paper Reading Behaviour}

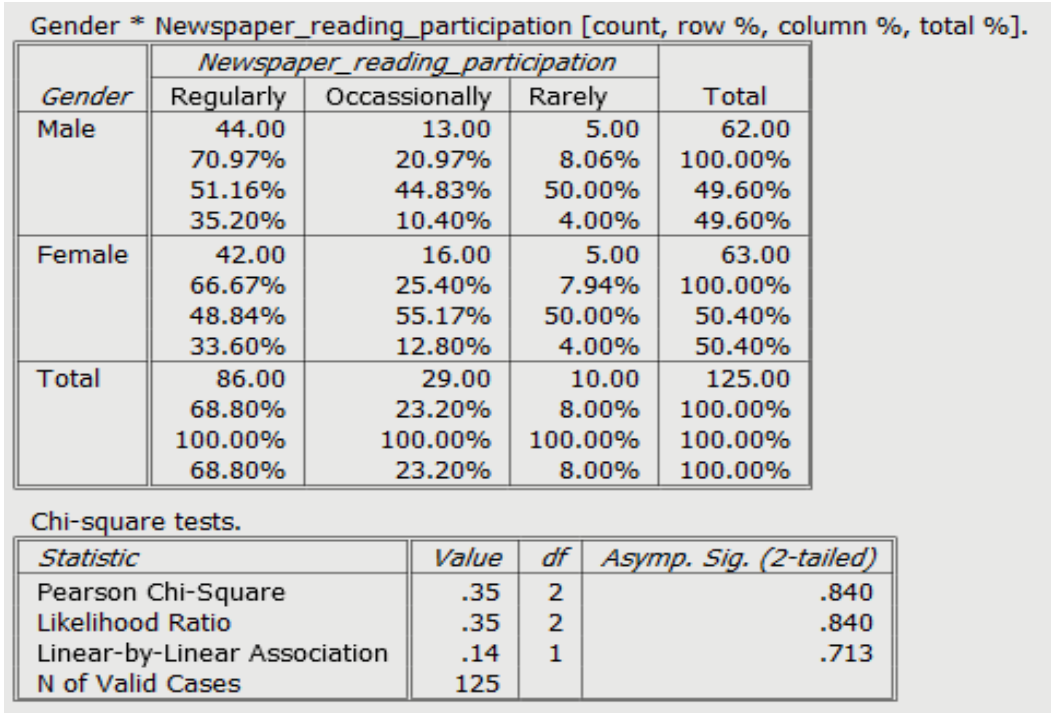

Figure 1: Cross Tabulation and Chi-square between Gender v/s Newspaper Reading Participation (Source: Authors' depiction)

According to this Chi-square test $p$-value $>0.05$ we can say gender has a significant effect on newspaper reading at a level of $5 \%$ significance.

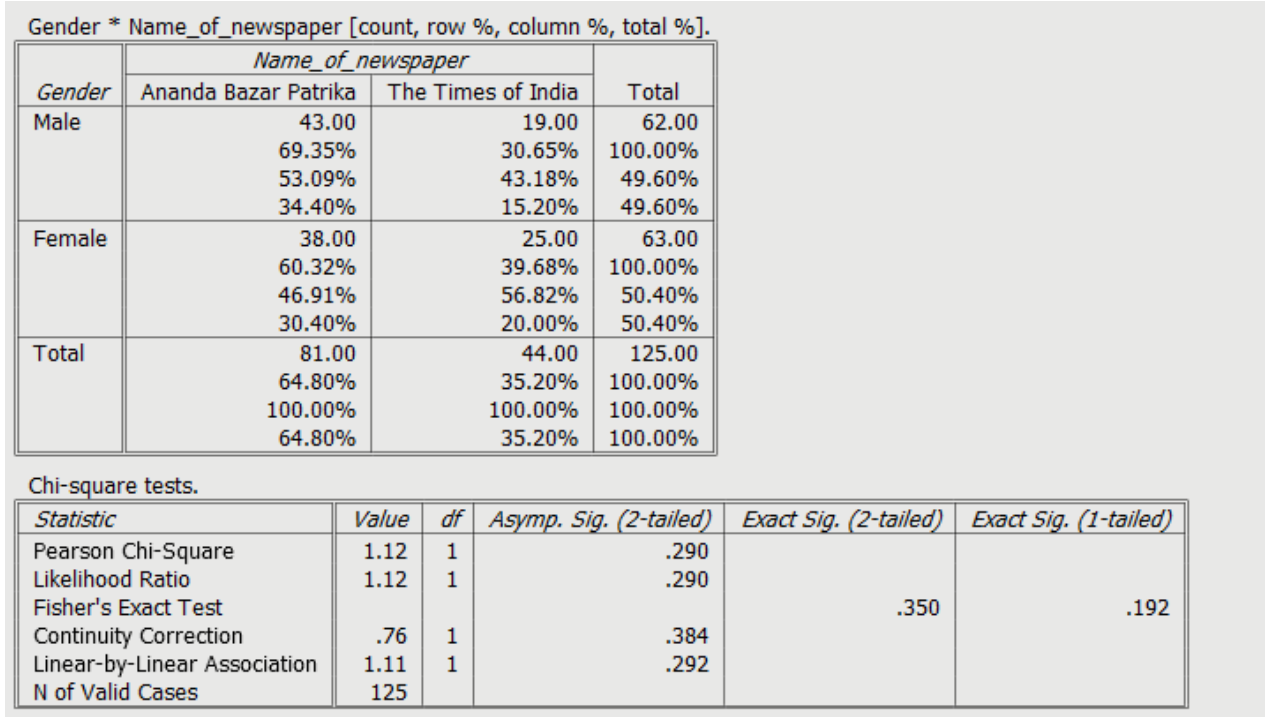

Figure 2: Cross Tabulation and Chi-square between Gender v/s Newspaper Read (Source: Authors' depiction)

According to this Chi-square test $p$-value $>0.05$, we can say gender has a significant effect on the newspaper at a level of $5 \%$ significance. 


\begin{tabular}{|c|c|c|c|c|c|c|c|}
\hline \multirow[b]{2}{*}{ Gender } & \multicolumn{6}{|c|}{ Type_of_news } & \multirow[b]{2}{*}{ Total } \\
\hline & Public Health & Technology & & olitical News & sports & entertainment & \\
\hline Male & $\begin{array}{r}6.00 \\
9.68 \% \\
18.18 \% \\
4.80 \%\end{array}$ & $\begin{array}{r}4.00 \\
6.45 \% \\
44.44 \% \\
3.20 \%\end{array}$ & & $\begin{array}{r}36.00 \\
58.06 \% \\
61.02 \% \\
28.80 \% \\
\end{array}$ & $\begin{array}{r}15.00 \\
24.19 \% \\
100.00 \% \\
12.00 \%\end{array}$ & $\begin{array}{r}1.00 \\
1.61 \% \\
11.11 \% \\
.80 \% \\
\end{array}$ & $\begin{array}{r}62.00 \\
100.00 \% \\
49.60 \% \\
49.60 \% \\
\end{array}$ \\
\hline Female & $\begin{array}{r}27.00 \\
42.86 \% \\
81.82 \% \\
21.60 \%\end{array}$ & $\begin{array}{r}5.00 \\
7.94 \% \\
55.56 \% \\
4.00 \% \\
\end{array}$ & & $\begin{array}{r}23.00 \\
36.51 \% \\
38.98 \% \\
18.40 \%\end{array}$ & $\begin{array}{r}.00 \\
.00 \% \\
.00 \% \\
.00 \%\end{array}$ & $\begin{array}{r}8.00 \\
12.70 \% \\
88.89 \% \\
6.40 \%\end{array}$ & $\begin{array}{r}63.00 \\
100.00 \% \\
50.40 \% \\
50.40 \%\end{array}$ \\
\hline Total & $\begin{array}{r}33.00 \\
26.40 \% \\
100.00 \% \\
26.40 \% \\
\end{array}$ & $\begin{array}{r}9.00 \\
7.20 \% \\
100.00 \% \\
7.20 \% \\
\end{array}$ & & $\begin{array}{r}59.00 \\
47.20 \% \\
100.00 \% \\
47.20 \% \\
\end{array}$ & $\begin{array}{r}15.00 \\
12.00 \% \\
100.00 \% \\
12.00 \% \\
\end{array}$ & $\begin{array}{r}9.00 \\
7.20 \% \\
100.00 \% \\
7.20 \% \\
\end{array}$ & $\begin{array}{r}125.00 \\
100.00 \% \\
100.00 \% \\
100.00 \% \\
\end{array}$ \\
\hline \multicolumn{6}{|c|}{ Chi-square tests. } & & \\
\hline \multicolumn{2}{|c|}{ Statistic } & Value & $d f$ & \multicolumn{2}{|c|}{ Asymp. Sig. (2-tailed) } & & \\
\hline \multicolumn{2}{|c|}{$\begin{array}{l}\text { Pearson Chi-Square } \\
\text { Likelihood Ratio } \\
\text { Linear-by-Linear Association } \\
\mathrm{N} \text { of Valid Cases }\end{array}$} & $\begin{array}{r}36.78 \\
44.44 \\
10.63 \\
125\end{array}$ & $\begin{array}{l}4 \\
4 \\
1\end{array}$ & & $\begin{array}{l}.000 \\
.000 \\
.001\end{array}$ & & \\
\hline
\end{tabular}

Figure 3: Cross Tabulation and Chi-square between Gender v/s Type of News (Source: Authors' depiction)

According to this Chi-square test $p$-value $\leq 0.05$, we can say gender has no significant effect on the type of news read.

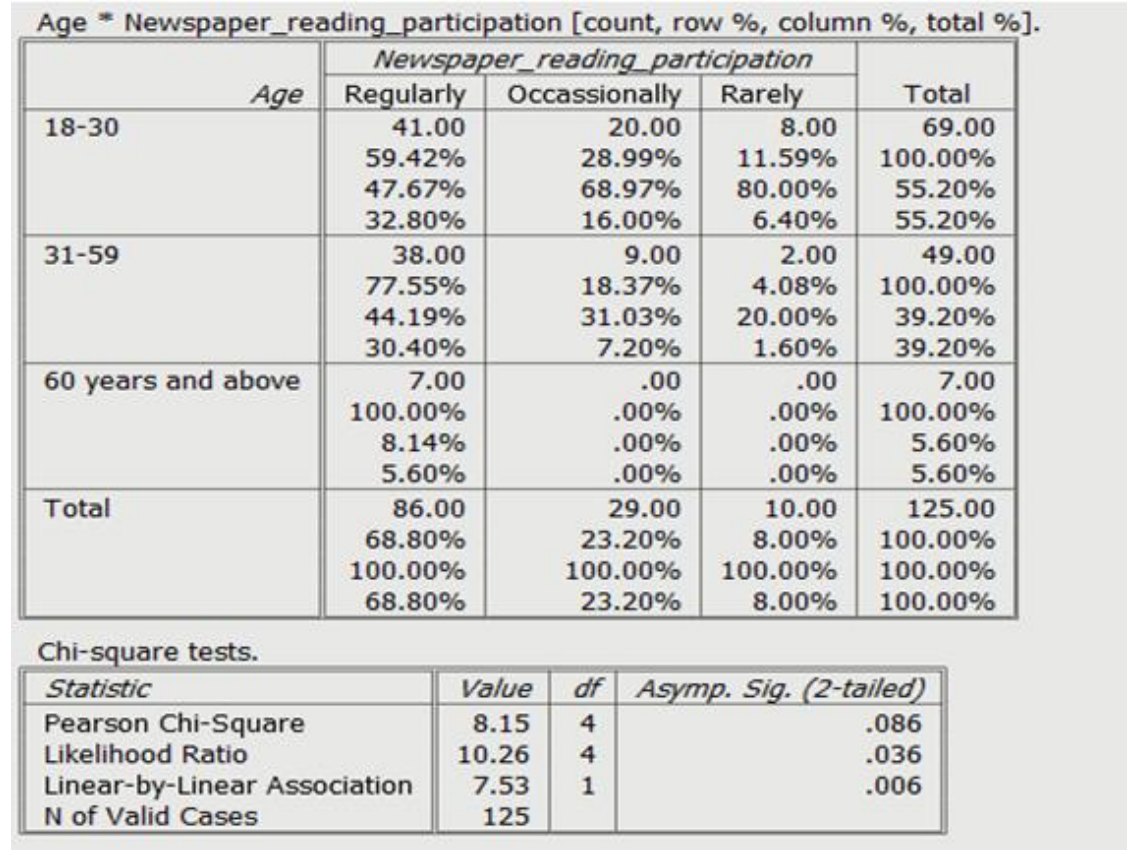

Figure 4: Cross Tabulation and Chi-square between Age v/s Newspaper Reading Participation (Source: Authors' depiction) 
According to this Chi-square test $p$-value $>0.05$, we can say age has a significant effect on newspaper reading at a level of $5 \%$ significance.

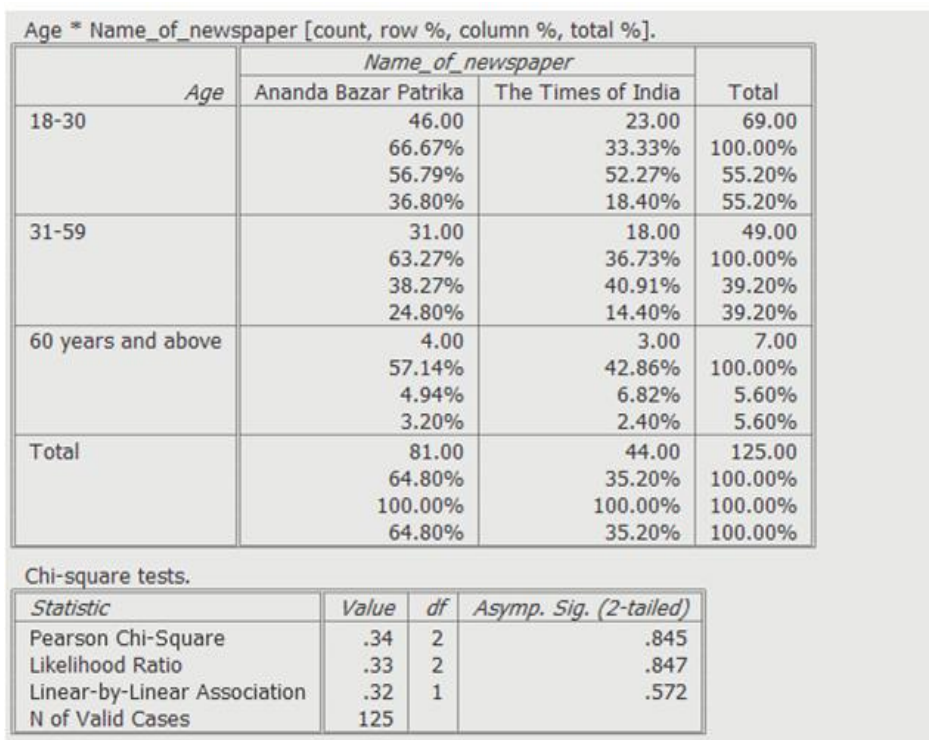

Figure 5: Cross tabulation and Chi-square between Gender v/s Newspaper Read (Source: Authors' depiction)

According to this Chi-square test $p$-value $>0.05$, we can say age has a significant effect on newspaper read at a level of $5 \%$ significance.

\begin{tabular}{|c|c|c|c|c|c|c|c|c|}
\hline \multirow[b]{2}{*}{ Age } & \multicolumn{7}{|c|}{ Type_of_news } & \multirow[b]{2}{*}{ Total } \\
\hline & Public & Health & Tech & inology & Political News & sports & entertainment & \\
\hline $18-30$ & & $\begin{array}{l}18.00 \\
5.09 \% \\
4.55 \% \\
4.40 \%\end{array}$ & & $\begin{array}{r}8.00 \\
1.59 \% \\
38.89 \% \\
6.40 \%\end{array}$ & $\begin{array}{r}27.00 \\
39.13 \% \\
45.76 \% \\
21.60 \%\end{array}$ & $\begin{array}{r}8.00 \\
11.59 \% \\
53.33 \% \\
6.40 \%\end{array}$ & $\begin{array}{r}8.00 \\
11.59 \% \\
88.89 \% \\
6.40 \%\end{array}$ & $\begin{array}{r}69.00 \\
100.00 \% \\
55.20 \% \\
55.20 \%\end{array}$ \\
\hline $31-59$ & & $\begin{array}{l}12.00 \\
.49 \% \\
.36 \% \\
.60 \% \\
\end{array}$ & & $\begin{array}{r}1.00 \\
2.04 \% \\
1.11 \% \\
.80 \%\end{array}$ & $\begin{array}{r}28.00 \\
57.14 \% \\
47.46 \% \\
22.40 \%\end{array}$ & $\begin{array}{r}7.00 \\
14.29 \% \\
46.67 \% \\
5.60 \%\end{array}$ & $\begin{array}{r}1.00 \\
2.04 \% \\
11.11 \% \\
.80 \%\end{array}$ & $\begin{array}{r}49.00 \\
100.00 \% \\
39.20 \% \\
39.20 \%\end{array}$ \\
\hline 60 years and above & & $\begin{array}{r}3.00 \\
2.86 \% \\
2.09 \% \\
2.40 \% \\
\end{array}$ & & $\begin{array}{r}.00 \\
.00 \% \\
.00 \% \\
.00 \%\end{array}$ & $\begin{array}{r}4.00 \\
57.14 \% \\
6.78 \% \\
3.20 \% \\
\end{array}$ & $\begin{array}{l}.00 \\
.00 \% \\
.00 \% \\
.00 \%\end{array}$ & $\begin{array}{r}.00 \\
.00 \% \\
.00 \% \\
.00 \%\end{array}$ & $\begin{array}{r}7.00 \\
100.00 \% \\
5.60 \% \\
5.60 \% \\
\end{array}$ \\
\hline Total & & $\begin{array}{l}33.00 \\
5.40 \% \\
.00 \% \\
5.40 \% \\
\end{array}$ & & $\begin{array}{r}9.00 \\
7.20 \% \\
0.00 \% \\
7.20 \%\end{array}$ & $\begin{array}{r}59.00 \\
47.20 \% \\
100.00 \% \\
47.20 \% \\
\end{array}$ & $\begin{array}{r}15.00 \\
12.00 \% \\
100.00 \% \\
12.00 \% \\
\end{array}$ & $\begin{array}{r}9.00 \\
7.20 \% \\
100.00 \% \\
7.20 \% \\
\end{array}$ & $\begin{array}{r}125.00 \\
100.00 \% \\
100.00 \% \\
100.00 \% \\
\end{array}$ \\
\hline \multicolumn{6}{|l|}{ Chi-square tests. } & & & \\
\hline \multicolumn{2}{|l|}{ Statistic } & Value & $d f$ & \multicolumn{2}{|c|}{ Asymp. Sig. (2-tailed) } & & & \\
\hline \multicolumn{2}{|c|}{$\begin{array}{l}\text { Pearson Chi-Square } \\
\text { Likelihood Ratio } \\
\text { Linear-by-Linear Association } \\
\mathrm{N} \text { of Valid Cases }\end{array}$} & $\begin{array}{r}12.31 \\
14.88 \\
.72 \\
125\end{array}$ & $\begin{array}{l}8 \\
8 \\
1\end{array}$ & & $\begin{array}{l}.138 \\
.062 \\
.396\end{array}$ & & & \\
\hline
\end{tabular}

Figure 6: Cross tabulation and Chi-square between Gender v/s Type of News (Source: Authors' depiction) 
According to this Chi-square test $p$-value $>0.05$, we can say age has a significant effect on the type of news read at a level of $5 \%$ significance.

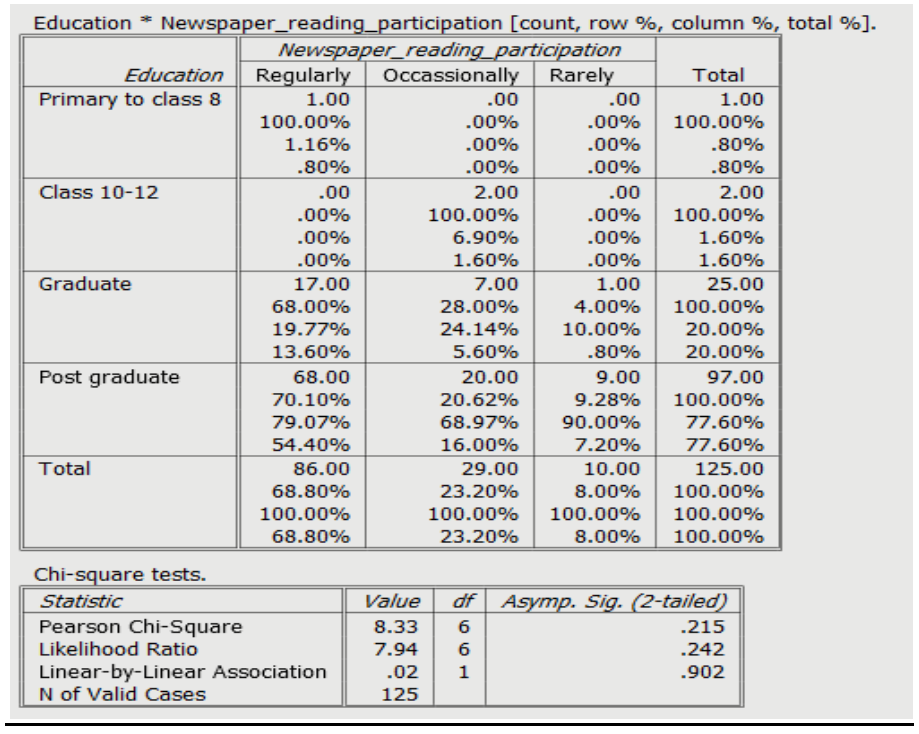

Figure 7: Cross tabulation and Chi-square between Education v/s Newspaper Reading Participation (Source: Authors' depiction)

According to this Chi-square test $p$-value $>0.05$, we can say education has a significant effect on newspaper reading at a level of $5 \%$ significance.

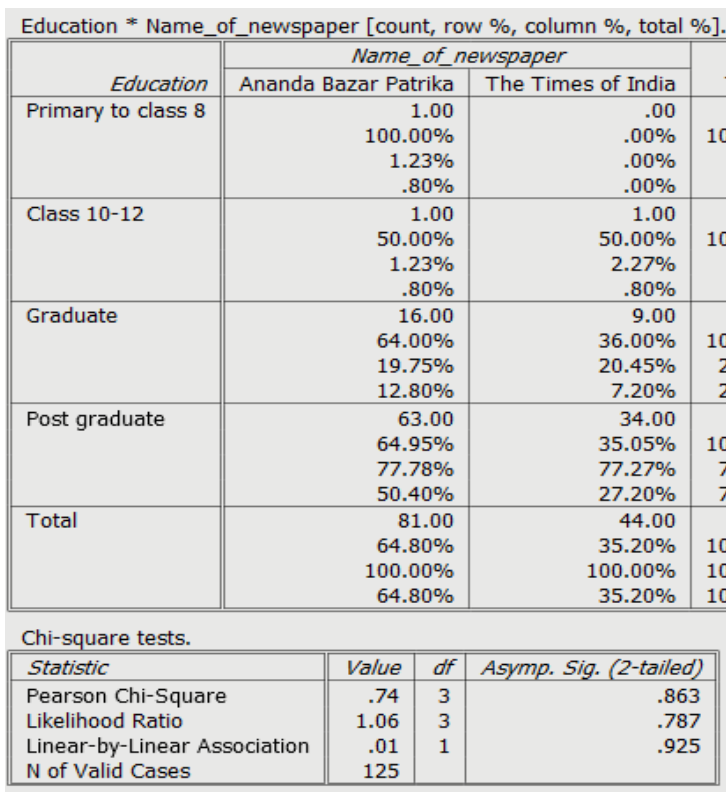

Figure 8: Cross tabulation and Chi-square between Education v/s Newspaper Read (Source: Authors' depiction) 
According to this Chi-square test $p$-value $>0.05$, we can say education has a significant effect on newspaper reading at a level of $5 \%$ significance.

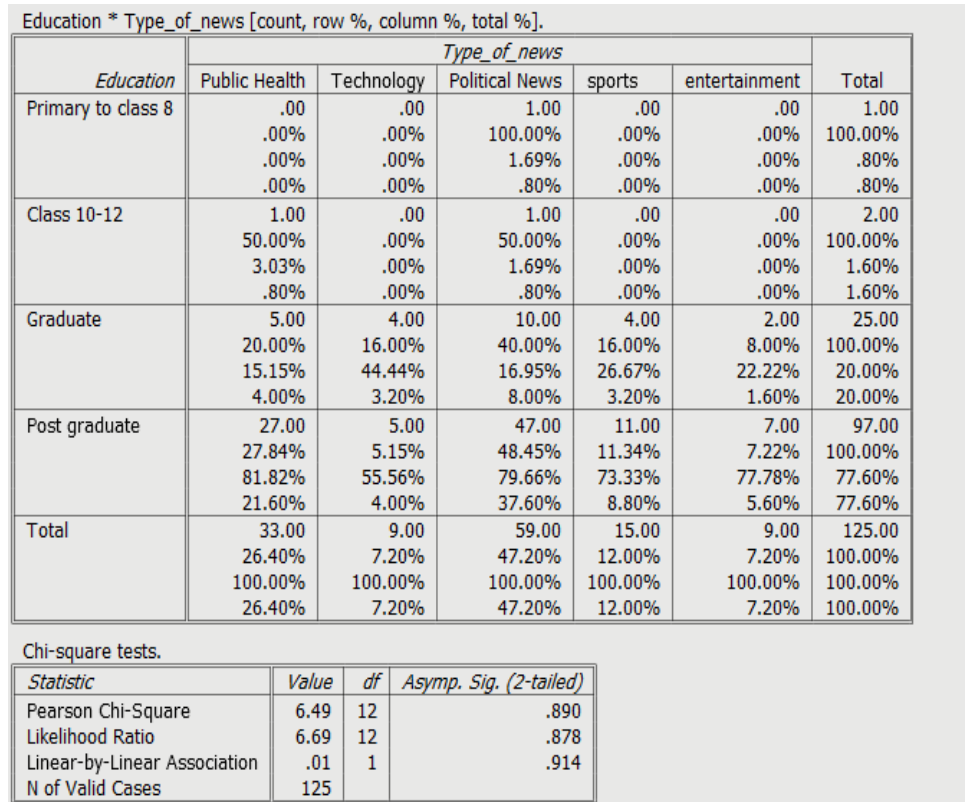

Figure 9: Cross tabulation and Chi-square between Education v/s Type of News Read (Source: Authors' depiction)

According to this Chi-square test $p$-value $>0.05$, we can say education has a significant effect on the type of news read at a level of $5 \%$ significance.

\section{The Name of Newspaper v/s Type of Content and Their Execution}

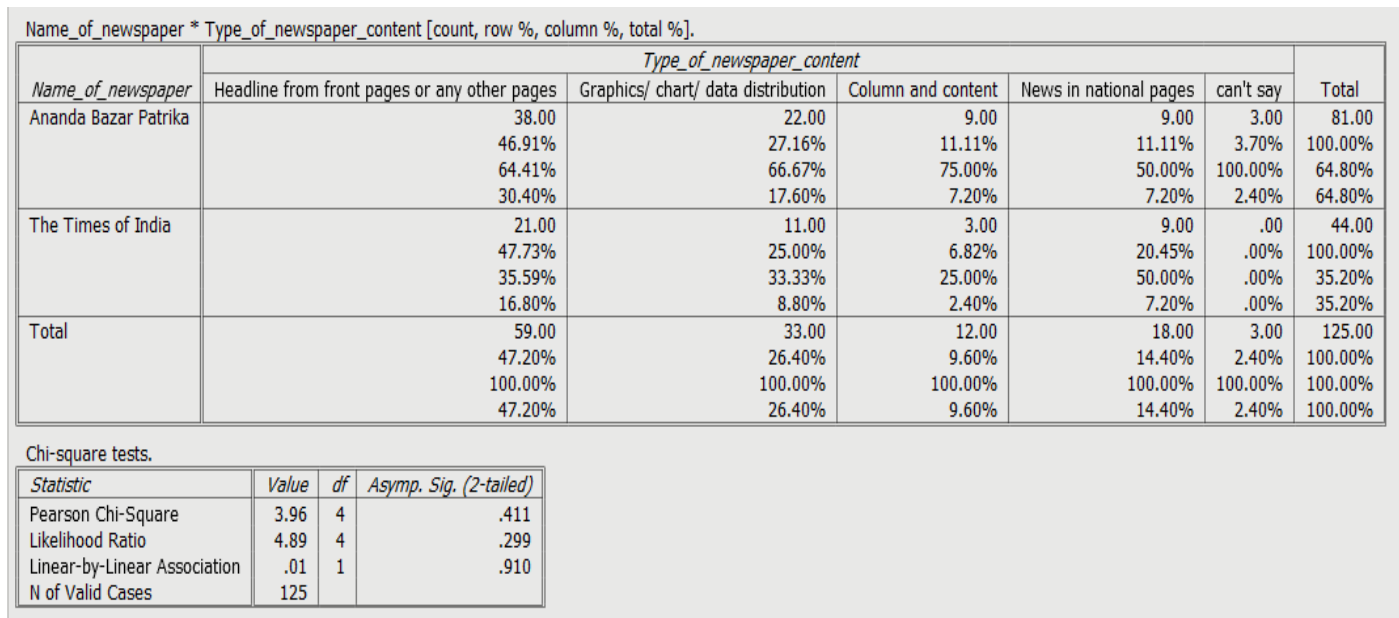

Figure 10: Cross Tabulation and Chi-square between Newspaper V/S Newspaper Content (Source: Authors' depiction) 
From Figure 10 it is observed that the respondents who read Anandabazar Patrika mostly prefer reading the headlines from the front pages of the newspaper denoted by 46.9 one percent of the respondents. On the other hand, the respondents who read the Times of India also emphasized that they mainly read headlines from front pages to understand the news value than that of the other types of newspaper content. According to this Chi-square test $p$-value $>0.05$, we can say the newspaper has a significant effect on the type of newspaper content at a level of $5 \%$ significance.

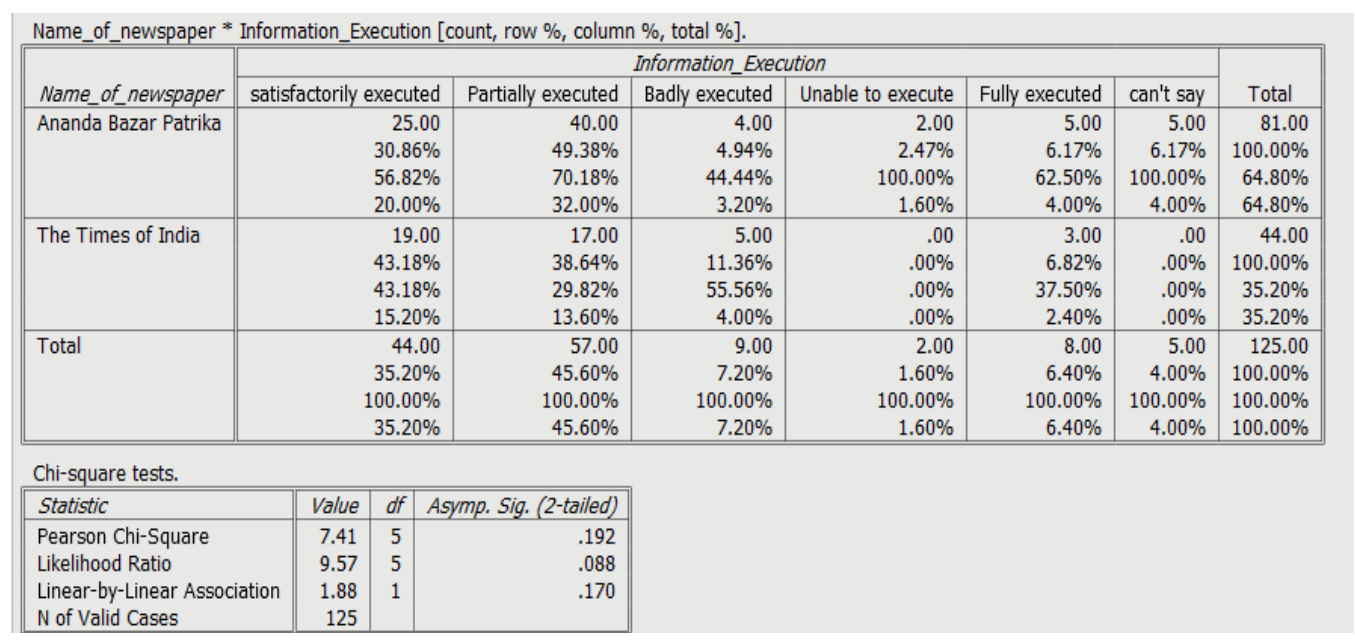

Figure 11: Cross tabulation and Chi-square between Newspaper v/s Information Execution (Source: Authors' depiction)

From Figure 11 it is noted that $49.9 \%$ of the readers of the Ananda Bazar Patrika said that the contents are partially executed in the newspaper. On the other hand the majority of the readers of The Times of India saint that the contents are satisfactorily executed in the newspaper. According to this Chi-square test $p$-value $>0.05$, we can say the newspaper has a significant effect on information execution at a level of $5 \%$ significance. 


\section{The Preference of News Content v/s Depiction of Newspaper Content}

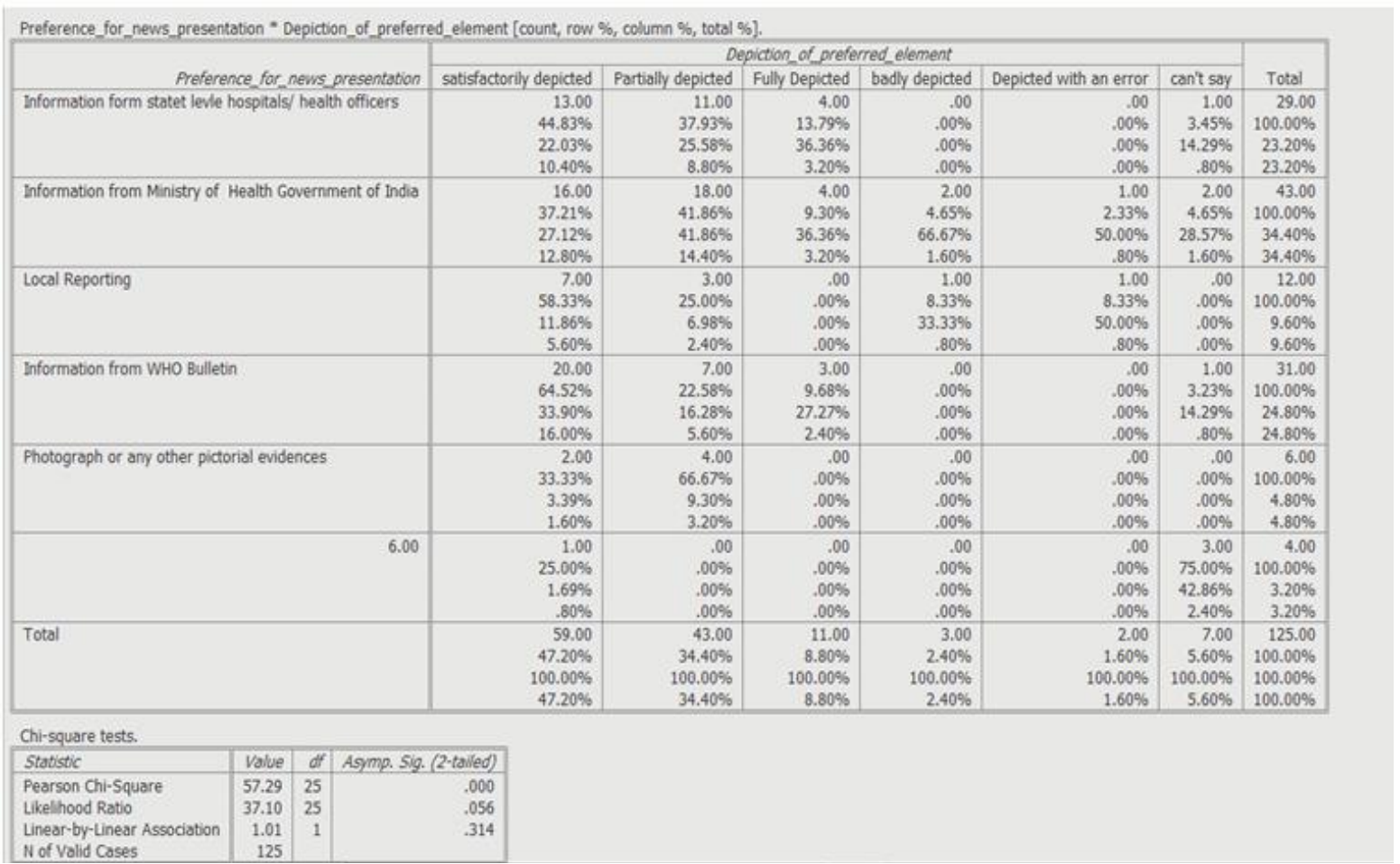

Figure 12: Cross tabulation and Chi-square between News Content Preferred v/s Newspaper Content Depicted (Source: Authors' depiction)

According to this Chi-square test $p$-value $\leq 0.05$, we can say preference of news content has no significant effect on the depiction of newspaper content.

Secondary Data Analysis

\section{Anandabazar Patrika}

On 16 March 2020 West Bengal first announced a full lockdown of all educational institutions, and partial lockdown in other sectors, due to the rising number of corona cases. The front page of the 16th March regional newspaper did not have any news of the West Bengal corona crisis, rather the first lead was of Maharashtra, which signifies, Bengal still did not have its first case. The precautionary measures have time and again been repeated on the national page, again on the regional page, and international page. The newspaper on 9 April, with a headline, "মেয়াদ বাড়লে কষ্ট করে চালান: মমতা", which loosely translates to, if the term is extended, adjust with difficulty. By the end of April, the solidarity with government officials, police, and health officials soon started dissolving. Headlines like "আক্রান্ত পুলিশ", means attacks on police officials in several 
places while doing their Covid-19 duty, started in. The discourse here is provocative towards health and government officials. May onwards, another few started invading, like, 'Red Zone', 'Green Zone' and 'Orange Zone'. The zones were marked as per the Covid-19 cases in the area, from the first May onwards. The awareness for the use of 'masks' and 'sanitizer' took the secondary option, whereas the main focus was spotted on the number of cases in the area.

By June 2020, the news about Covid-19 or health awareness was hard to find in the first pages of regional newspapers conflict between the time India and China started. Social distancing started becoming a myth, by that time. Headlines like, "মন্দির খুলতেই অধরা দূরত্ববিধি" suggested the illusion of social distancing, as soon as the temple opened in Tarapith, a popular temple in West Bengal. This signifies the panic that was evident in April and started dissolving from June onwards. The tender attitude of the police officials has been blamed and for this reason, again complete lockdown in the whole state on 24 June 2020. The headline, "এবারকড়াহাতেলকডাউন", means, this time more stringent measures for lockdown, which suggests, there were slow down from the part of the officials in the previous month.

In September health communication through newspaper content started taking a new form. September was the month just before the biggest festival of West Bengal Durga Puja. The words, like, 'second wave', 'masks', 'social distancing' are found in every alternative news piece. There was a chance of a second corona wave in Bengal, in October, the awareness started in September.

From the discourse analysis of West Bengal's highest circulated regional newspaper, it is evident that a full circle has been covered from spreading awareness, to shifting towards stringent measures, to break the chain, to slow down measures, to more politically less health-related news, to again a bang on awareness creation.

\section{The Times of India}

This qualitative data analysis has been done considering the rhetoric that is the study of the language used in the contents of a newspaper and its discourse that is its application beyond the text. While analyzing The Times of India with the help of the constructed weeks it was observed that. Initially, in the beginning, the front page consisted of words like 'Corona fear' and 'test reports' which shows that the elements of fear have been used as one of the major factors for making people aware of the rapid spread of the disease. In the latter weeks of March 2021, there was more picture graphical representation observed along with other data about coronavirus. Simultaneously the issues of migrant workers were also reflected on the front page. From 15 April 2020 The Times of India modified its logo with the ' $O$ ' of 'OF' reflecting a human face wearing a mask. This reflects that the newspaper not only introduced unique content but there was also uniqueness in their page-makeup. In May the 
newspaper focused on 'Lockdown 4.0' and the actions taken up by the government. In September there was almost no reflection of Covid-19 cases on the front page of the newspaper.

The Times City Page from the Kolkata edition represented issues like 'Temple crowds' and 'Social distancing' came into play to explain the precautions to be taken. During the later period of March, this segment reported the need for the administration to look after supply chain issues in the post lockdown phase. New issues like 'supply hiccups' and 'Corona victim's cremation' were reported. Just like the front page, the discourse of the city page was kept quite similar where the 'End of lockdown 3.0' and future issues were highlighted on the city page and still concentrates on the extension of lockdown till 31 of July.

On the national page along with the number of deaths and rise of cases, there was also a reflection of political issues among different political parties. Headlines like 'Didi writes to $18 \mathrm{CM}^{\prime}$ talk about political conflicts and the need for political unity to help the migrant workers traveling in that scenario. On the other hand, the international pages reflected the steps that were taken up by other countries using words like "Europe Locks Itself (...)", to emphasize the importance of lockdown. The international page during May 2020, focused on Donald Trump and the condition of the US 'claiming all is well' expressed in a pun intended nature. There was a reduced number of news on Covid-19 on national and international pages from August 2020. Similar to the front page the global and the national pages.

\section{DISCUSSION}

The majority of both male and female respondents had been regularly reading newspapers with $70.97 \%$ male respondents and $66.67 \%$ female respondents respectively. Moreover, gender was found to be significantly influencing the newspaper reading behavior of the respondents. After the statistical data analysis, it is also clear from Figure 2 denotes that female respondents read more news on public health than male respondents. Out of all the factors the majority of the male respondents preferred to need political news from that of the news on public health. Other factors like education and age are also significantly influencing newspaper reading behavior. The older generations are more regular readers of newspapers than that of the younger generation. News on public health is read more by the age group of 60 years and above than that of the younger generation who are more interested in political news.

If the content design is considered then it was observed that the newspaper readers of both Anandabazar Patrika and The Times of India mostly follow the headline of the front page to understand the value of the news presented. Moreover, content execution of the Times of India was noted to be satisfactorily executed than that of the Anandabazar Patrika which was found to have been partially executed. 
From the qualitative data analysis of The Times of India, it was observed that initially, the newspaper used the elements of fear with the choice of its language as well as their application to aware people against the pandemic in the third week of March 2020. Gradually the discourse changed from fear to updates about initiatives taken up by the Central as well as State governments. Then, in June and July 2020, the number of cases, the rate of recovery, and Covid-19 warriors were the major focus of the newspaper. In August and September 2020, there were very few news articles about Covid-19 observed across different pages. If the concept of audience analysis after McQuail (1997) is considered then the perception of the audience is necessary to consider while determining the effect of content.

From the primary data analysis, it was observed that the front page headlines play a very crucial role in the choice of the respondents. It was also observed from the opinion of Jeffery (2000) that newspapers are one of the most effective tools of communication during the Covid-19 pandemic. Similarly, it was observed from the quantitative data analysis that the audience considers newspapers to be the most authentic medium of communication. In addition to this newspapers have also been useful in promoting scientific methods of health. Yet, it was also noted that the majority of respondents prefer TV and social media over newspapers for getting Covid-19 related updates.

\section{CONCLUSION}

It can be concluded that media advocacy supports a significant discourse of social cognitive behavior through newspaper content during the Covid-19 pandemic. During the first few months, the element of fear was found to be prevailing among the newspapers. Gradually, it was the front-page headlines that showed considerable variations in their discourses. From the analysis of the audience behavior, it was also noted that newspaper is one of the potential mediums of communication yet the audience has a preference for modern gadgets when it comes to receiving information about the disease. So, it can be observed that along with newspapers there are other mediums of communication especially the new media which is being preferred by the audience. Yet, considering the authenticity and accuracy of content it can be concluded that newspapers are the most crucial medium for disseminating information to the audience during the pandemic. It is through the promotion of scientific knowledge that newspapers have been keeping pace with media advocacy during the Covid-19 pandemic in Kolkata. 


\section{ACKNOWLEDGMENTS}

We express our sincerest regards to the Indian Council of Social Science Research (ICSSR, MHRD) for supporting our research work. We acknowledge their contribution to our research work and for helping us to research health communication and allied fields. 


\section{REFERENCES}

1. Allen, L.D. and Ayalon, L., 2021. "It's pure panic": The portrayal of residential care in American newspapers during COVID-19. The Gerontologist, 61(1), pp.86-97 https://doi.org/10.1093/geront/gnaa162

2. Choi, M. and McKeever, B.W., 2019. News framing of avian flu: Media advocacy and response to a public health crisis. Newspaper Research Journal, 40(4), pp.451-466. https://doi.org/10.1177\%2F0739532919855790

3. Chukwu-Okoronkwo, S.O., 2020. Covid-19 Pandemic Media Sensitisation Campaign in Nigeria and the" Marginalised Ears". The Journal of Development Communication, 31(2), pp.24-33. http://jdc.journals.unisel.edu.my/ojs/index.php/jdc/issue/view/17

4. Friedler, A., 2021. Sociocultural, behavioral and political factors shaping the COVID-19 pandemic: the need for a biocultural approach to understanding pandemics and (re) emerging pathogens. Global Public Health, 16(1), pp.17-35. https://doi.org/10.1080/17441692.2020.1828982

5. McQuail, D., 1997. Audience analysis. Sage publications.

6. Pham, L.T.M., 2018. Qualitative approach to research a review of advantages and disadvantages of three paradigms: Positivism, interpretivism, and critical inquiry. University of Adelaide. https://www.researchgate.net/profile/Lan-Pham3/publication/324486854 A Review of key paradigms positivism interpretivism and_critical_inquiry/links/5acffa880f7e9b18965cd52f/A-Review-of-keyparadigms-positivism-interpretivism-and-critical-inquiry.pdf

7. Riffe, D., Aust, C.F. and Lacy, S.R., 1993. The effectiveness of random, consecutive day and constructed week sampling in newspaper content analysis. Journalism Quarterly, 7a1), pp.133-139. https://doi.org/10.1177\%2F107769909307000115

8. Thirumaran, K., Mohammadi, Z., Pourabedin, Z., Azzali, S. and Sim, K., 2021. COVID-19 in Singapore and New Zealand: Newspaper portrayal, crisis management. Tourism Management Perspectives, 38, p.100812. https://www.sciencedirect.com/science/article/abs/pii/S2211973621000258

9. Vilbert, J., 2021. Global health governance post-Covid-19: time for a hierarchical order?. Journal of Liberty and International Affairs, 7(2), pp.11-30. https://doi.org/10.47305/JLIA21720011v

10. Woiceshyn, J. and Daellenbach, U., 2018. Evaluating inductive vs deductive research in management studies: Implications for authors, editors, and reviewers. Qualitative Research in Organizations and Management: An International Journal. https://doi.org/10.1108/QROM-06-2017-1538 


\section{Annex I: Constructed Weeks}

\begin{tabular}{|l|c|c|c|}
\hline \multicolumn{1}{|c|}{ Days } & \multicolumn{3}{c|}{ Date (Constructed Weeks) } \\
\hline Monday & 16.03 .2020 & 18.05 .2020 & 20.07 .2020 \\
\hline Tuesday & 12.05 .2020 & 14.07 .2020 & 15.09 .2020 \\
\hline Wednesday & 22.04 .2020 & 24.06 .2020 & 26.08 .2020 \\
\hline Thursday & 09.04 .2020 & 04.06 .2020 & 06.08 .2020 \\
\hline Friday & 27.03 .2020 & 29.05 .2020 & 24.07 .2020 \\
\hline Saturday & 09.05 .2020 & 11.07 .2020 & 05.09 .2020 \\
\hline Sunday & 03.05 .2020 & 14.06 .2020 & 30.08 .2020 \\
\hline
\end{tabular}

